\title{
The Relationship of Psychosocial Dysfunction and Stunting of Adolescents in Suburban, Indonesia
}

\author{
Dwi Oktari Erfanti, Djatnika Setiabudi, Kusnandi Rusmil \\ Department of Child health, Faculty of Medicine, Universitas Padjadjaran-Hasan Sadikin Hospital, Bandung, Indonesia \\ Email:dr.tari.ika81@gmail.com
}

How to cite this paper: Erfanti, D.O., Setiabudi, D. and Rusmil, K. (2016) The Relationship of Psychosocial Dysfunction and Stunting of Adolescents in Suburban, Indonesia. Open Journal of Medical Psychology, 5, 57-65.

http://dx.doi.org/10.4236/ojmp.2016.54007

Received: July 8, 2016

Accepted: September 5, 2016

Published: September 8, 2016

Copyright $\odot 2016$ by authors and Scientific Research Publishing Inc. This work is licensed under the Creative Commons Attribution International License (CC BY 4.0).

http://creativecommons.org/licenses/by/4.0/

\begin{abstract}
The purpose of this study was to investigate the psychosocial dysfunction of adolescents with stunted and normal height. This was a cross-sectional study using pediatric symptom checklist-17 (PSC-17), subjected to adolescents (age: 11 to 14 years) in Suburban, West Java Indonesia. Two variables of the subjects' characteristics (sex and body height) were included in the multivariate analysis because the $\mathrm{p}$ was $<0.25$ $(\mathrm{p}=0.22, \mathrm{p}=0.07)$. It was found that 53 subjects had psychosocial dysfunction ( 25 stunted, 4 severely stunted, and 24 normal heights) with significant comparing proportion between severely stunted and normal height $(\mathrm{p}=0.04)$. In severely stunted adolescents, the risk of psychosocial dysfunction is 6.33 more than in normal stature group. Examination was done on those 53 adolescents resulted in several psychosocial disorders: 12 psychosocially low self-esteem, 12 family problems, and others ranging from other several aspect problems. Forty-one from the 53 adolescents were with psychopathology symptoms. There was psychosocial dysfunction just in adolescents with severely stunted.
\end{abstract}

\section{Keywords}

Psychosocial Dysfunction, Stunted, PSC-17

\section{Introduction}

Stunting in children has taken attention in the last few decades, because the incidence is still high especially in developing countries, and it affects 167 millions on 2010 [1]. For adolescents, in 2013 it represented $35.1 \%$ cases in Indonesia as one of developing countries [2]. Globally, the reduction is still under the target of 2020 (142 million stunted children), even there is a reduction in the last two decades. While stunting becomes one of the major health problems in developing countries, this condition still has no focus 
attention from the government [1].

Psychosocial disorders of stunting begin in adolescence [3] [4]. Adolescents were characterized by rapid changes in the bio-psychosocial aspects of physical, emotional and social maturation that was influenced by various socio-demography factors. In this period of time, the physical and social psychological maturation occurred [5] [6]. Several risk factors have been found to be associated with psychosocial disfunction in stunted adolescents such as gender, lower maternal and paternal education, lack of family income and poverty [7]. Studies have shown that more boys than girls are referred for short stature management [4]. Low parental education level and poverty can endanger adolescent's psychosocial health through exposure to a range of adversities, and these may include parent's stress, lack of warmth and love [8].

Stunted adolescents are prone to psychosocial disorder in three aspects (internalization, externalization and attention). They often feel alienated in their social community, having negative perception, social withdrawn, low self-esteem, and often depressed by becoming mockery targets for their friends [9]. Psychosocial disfunction might happen depending on the interaction of risk factors and resistance factors. Important risk factors for the psychological adjustment are the satisfaction with its height, the acceptance from environment, and psychosocial stress related to being bullied due to short stature. Important resistance factors of short stature might be the temperament, familial support and coping strategies [10].

In Indonesia, there is no data onto adolescents' stunted towards their psychosocial dysfunction. Therefore, it is important to assess the psychosocial dysfunction on stunted adolescents and examine the protection and precipitation factors as early detection and treatment of psychosocial problem.

\section{Method}

Subjects were adolescents aged 11 - 14 years with normal height according to World Health Organization height-to-age and with stunted $(<-2 \mathrm{SD})$, living in Jatinangor, West Java and willing to participate in the study. Exclusion criteria were stunted adolescent with accompanying defect such as chronically diseases or congenital defects and malnutrition. The Study was conducted in four junior high schools in Jatinangor from February to May 2015. The study method had had the ethical approval from the Ethical Committee of Medical Faculty of Padjajaran University and Hasan Sadikin Hospital in Bandung. The study was an analytical observation with cross-sectional method. Sample selection started from measuring students' height, followed by giving informed consent to obtain subject's approval for participating, filled the pediatric symptoms checklist 17 (PSC-17) questionnaire as early detection of psychosocial dysfunction in cognitive, emotion, and behavior. Psychosocial dysfunction aspects including five internal aspects (sad, easy to despair, anxiety, self-blame and seemed unhappy), seven external aspects (fighting, not paying attention to the rules, not understand the feelings of others, annoyed, blaming others for his own mistakes, refused to share and take the property of others), and five attention aspects (restless, daydreaming, easily switch attention, diffi- 
culty in concentrating, and move as controlled by an engine). The subject is assumed as psychosocial dysfunction if the result for internal aspects score $\geq 5$ or external aspect score $\geq 7$ or attention score $\geq 7$ or total score $\geq 15$ [11]. To know the type of psychosocial problems and psychopatology symptoms, we collaborated with Child Psychiatry Consultants in some steps examination such as indepth interview, Conner's rating scale for subjects, parents or teachers, House Tree Person test (HTP), and Depression Scale Test (DST). The data were using bivariate analysis, and then some factors might influence psychosocial dysfunction with $\mathrm{p}$-value $<0.25$ were used logistic regression for multivariate analysis. A p-value $<0.05$ was considered statistically significant. The statistical analysis of the data was performed with IBM SPSS (version 15.0 for Windows, IBM, NY, USA).

\section{Results}

The study was conducted in four junior high schools in Jatinangor, West Java, Indonesia. From 200 adolescents who met the inclusion criteria, 100 adolescents were categorized as stunted and 100 were normal height. General characteristics of the subject between stunted and normal stature can be seen in Table 1. Both in age group were homogenous with same proportion. Majority of students stayed with their parents. Number of family member living in the same roof and parents' occupation were not different between stunted and normal height adolescent groups. Democratic parenting style was dominant in both groups.

There are some independent variable which associated with psychosocial disfunction

Table 1. Characteristics of the study subject.

\begin{tabular}{|c|c|c|}
\hline \multirow{2}{*}{ Characteristic } & \multicolumn{2}{|c|}{ Height Category } \\
\hline & Stunted $(n=100)$ & Normal $(n=100)$ \\
\hline \multicolumn{3}{|l|}{ 1. Age (years) } \\
\hline Mean (SD) & $13.2(0.8)$ & $13.0(0.7)$ \\
\hline Range & $12-14$ & $11-14$ \\
\hline \multicolumn{3}{|l|}{ 2. Stay with parents } \\
\hline Yes & 96 & 96 \\
\hline No & 4 & 4 \\
\hline \multicolumn{3}{|c|}{ 3. Family member living in one roof } \\
\hline$\leq 4$ & 71 & 72 \\
\hline$>4$ & 29 & 28 \\
\hline \multicolumn{3}{|l|}{ 4. Parenting style } \\
\hline Democratic & 79 & 77 \\
\hline Authoritarian & 16 & 19 \\
\hline Permissive & 5 & 4 \\
\hline \multicolumn{3}{|l|}{ 5. Parents Occupation } \\
\hline Government employee & 6 & 12 \\
\hline Trader & 32 & 24 \\
\hline Laborer & 27 & 30 \\
\hline Farmer & 24 & 19 \\
\hline Entrepreneur & 11 & 15 \\
\hline
\end{tabular}


such as sex, mother education level, father education level, family's income and stunted condition (Table 2). From bivariate analysis, the result with $\mathrm{p}>0.05(\mathrm{p}=0.25)$ are sex $(\mathrm{p}=0.22)$ and body height $(\mathrm{p}=0.07)$.

There is sub independent variable (Table 3 ) which become significantly associated with psychosocial dysfunction, severely stunted is the strongest factor in psychosocial dysfunction compared with normal stature and $\mathrm{p}$ value $0.04(\mathrm{p}<0.05)$. Odd Ratio $(\mathrm{OR})$ is 6.33. It means that in severely stunted subjects, the risk possibility in psychosocial dysfunction is 6.33 times more than in normal stature group. Stunted group insignificance compared with normal group, sex was also not significant.

As shown in Table 4 from 53 refereed subjects that had psychosocial dysfunction, the examination result on each subject had discovered the type of psychosocial problem which were grouped into 12 cases on low self-esteem, 12 cases on family problems, academic problems in 8 cases, childhood abused background in 6 cases, 5 cases on

Table 2. Characteristics of the study subject associated with psychosocial dysfunction.

\begin{tabular}{|c|c|c|c|}
\hline \multirow{2}{*}{ Characteristic } & \multicolumn{2}{|c|}{ Psychosocial dysfunction } & \multirow{2}{*}{ p value } \\
\hline & No & Yes & \\
\hline \multicolumn{4}{|l|}{ 1. Sex } \\
\hline Boys & 67 & 19 & 0.22 \\
\hline Girls & 80 & 34 & \\
\hline \multicolumn{4}{|l|}{ 2. Mother education level } \\
\hline Primary school & 61 & 21 & \\
\hline Middle school & 49 & 19 & 0.94 \\
\hline High school & 32 & 12 & \\
\hline University/Academy & 5 & 1 & \\
\hline \multicolumn{4}{|l|}{ 3. Father education level } \\
\hline Primary school & 56 & 19 & 0.99 \\
\hline Middle school & 39 & 15 & \\
\hline High school & 43 & 16 & \\
\hline University/Academy & 9 & 3 & \\
\hline \multicolumn{4}{|l|}{ 4. Family income } \\
\hline$\geq 2$ Million/Month & 14 & 7 & 0.45 \\
\hline$<2$ Million/Month & 133 & 46 & \\
\hline \multicolumn{4}{|l|}{ 5. Body height } \\
\hline Normal & 76 & 24 & 0.07 \\
\hline Stunted & 69 & 25 & \\
\hline Severely stunted & 2 & 4 & \\
\hline
\end{tabular}

${ }^{\star}$ Bivariate analysis (chi square).

Table 3. The final multivariate analysis between independent variable and psychosocial dysfunction.

\begin{tabular}{ccc}
\hline Variable & p value $^{*}$ & OR (95\% CI) \\
\hline 1. Stunted & \\
-Stunted (stunted) & & $1.15(0.60-2.19)$ \\
-Severely stunted & 0.68 & $6.33(1.09-36.75)$ \\
\hline
\end{tabular}

${ }^{*}$ Logistic regression analysis backward stepwise, ${ }^{*}$ Reference $:$ Normal stature. 
bullying historical background, lovers in 1 case, neglected child in 2 cases, 5 cases on anxiety, and 2 cases on siblings' rivalry.

In Table 5, it was found that 41 cases were included in psychopathology symptoms; there were 7 cases on anxiety disorder, depression in 18 cases, 2 cases on conduct disorder, and 1 case on bipolar disorder.

\section{Discussion}

The psychosocial dysfunction occurrence might be caused by internal and external factors. The internal factors were coming from the self, the feeling different from others and the desire to have a good and proportional height. With this internal factors, stunted adolescent had low self-esteem and prone to depression. The external factors were derived from stigmatized environment to stunted adolescent. Family factors that affected the adolescent were parent to child relationship pattern, social class and economy status [7] [10].

Table 4. The type of psychosocial problems between severely stunted, stunted, and normal height adolescents.

\begin{tabular}{cccc}
\hline \multirow{2}{*}{ Psychosocial type of problem } & \multicolumn{3}{c}{ Height category } \\
\cline { 2 - 4 } & Severely stunted & Stunted & Normal \\
\hline Low self-esteem & 1 & 4 & 7 \\
Family problem & 1 & 7 & 4 \\
Academic problem & - & 5 & 3 \\
Childhood abused background & 1 & 3 & 2 \\
Bullying & 1 & 3 & 1 \\
Anxiety & - & 2 & 3 \\
Sibling rivalry & - & - & 2 \\
Lovers & - & 1 & - \\
Neglected child & - & - & 2 \\
Sub-total & $\mathbf{4}$ & $\mathbf{2 5}$ & $\mathbf{2 4}$ \\
\hline
\end{tabular}

Table 5. The psychopathology symptoms between severely stunted, stunted, and normal height adolescents.

\begin{tabular}{cccc}
\hline \multirow{2}{*}{ Psychopathology type of symptoms } & \multicolumn{3}{c}{ Height category } \\
\cline { 2 - 4 } & Severely stunted & Stunted & Normal \\
\hline Depression & 2 & 9 & 7 \\
Anxiety disorder & - & 3 & 4 \\
Hyperactivity and concentrating problem & - & 3 & 2 \\
ADHD & 2 & 4 & 2 \\
Conduct disorder & - & 2 & - \\
Bipolar disorder & - & - & 1 \\
Sub-total & $\mathbf{4}$ & $\mathbf{2 1}$ & $\mathbf{1 6}$ \\
\hline
\end{tabular}


Stunted adolescent is not always having psychosocial problem. There are protective and risk factors that associated with shape the adolescent personality. The protective factors are factors that will modify, change, or make a person stronger to encounter challenges from surrounding environment. This Factor will help adolescents to reach the positive development of psychology, eventhough there are some risk factors might danger development [7].

These protective factors interaction with risk factors will result in the presence of behavior, emotional, or mental disorders. Some protective factors are: positive characters/personality, supportive family environment, social environment as support system to strengthen the adolescent adaptive ability, good social skills and intellectual level. [12] [13]. Risk factors on stunted are psychosocial stress such as bullying and negative attitude from their peers, also inability or malfunction independence in their daily life, that will doubt the development of psychology and adolescents will treat unsuitable on their age (juvenilization) [10] [14].

A Study on psychosocial aspect's early behavior on stunted adolescent had found that stunting were associated with the stigmatization related to psychosocial stress [15]. It was also reported that social adaptation problem were associated with social immaturities. Stunted children are physically weaker than other causing over protection from parents. This is a strong predictor of victimization from friends of the same age [9].

In this study, the comparison between two-height groups had significant difference between severely stunted and normal height on psychosocial disfunction, severely stunted in adolescents has a possibility of 6.33 more than normal stature. This condition caused by internal factors of the severely stunted that make them introvert and low self esteem, the eksternal factors caused by stigmatization, lack of family support, the risk factors caused by bullying and juvenilization and the protective factors could not reverse the risk factors.

The condition on stunted group was not significantly difference with normal group because most of them had less psychosocial stress, the physical condition were not much difference so they had less stigmatization, juvenilization and they had more family support.

Stunted adolescents have worse psychosocial function than normal height adolescents [16]. The psychosocial disorder, which is often found on both height groups, was internalization. The internalization problem occurred in teenager period of age; when the physical, social, emotion, moral, and personality development happened at the same time [5]. The domination of internalization disorder happened because teenagers start to have self-conception and embarrassment that affected to self-judgment. In our study, there were no significant differences on internalization, externalization and behavior aspects.

The subject in this group were most female (57\%), while male (43\%). The influence of gender to psychosocial dysfunction using multivariate analysis was not significant $(p>0.05)$. The incident of psychosocial dysfunction was found more in females because females adolescent had more attention on their physical performance and they often 
compare their performance with others.

From total sample, only 3\% mothers had higher level of education. Mother with low education level might lead to poor parenting style and unable to handle a stressor. Fathers' education level was lower in stunted adolescent and could affect the family income and social economics. Family with low income are often felt anxious and depressed that lead to unresponsive parenting and lack of caring their children that might promote children behavior disorder. Some studies also found that poverty is one of the risk factor to psychosocial dysfunction in children [8] [17].

The mother's and father's education and family income might not cause significant difference on psychosocial dysfunction, it because the family characteristics in suburban area in this study referring parents education and family income between stunted and normal groups tend to be similar, and the family in the suburban area find this condition as normal and not a problem.

In this study, there were 94 stunted and 6 severely stunted adolescents. From further examination, there were 53 adolescents with psychosocial dysfunction consisted of 25 stunted, 4 severely stunted, and 24 normal height adolescent as control group. Examination result by child psychiatrist consultant toward these 53 adolescent had discovered psychosocial dysfunction types of problems. Low self-esteem (12 cases), family problem (12 cases) were main problems, other problems were academic problems (8 cases), child abused background ( 6 cases), bullying ( 5 cases), lovers ( 1 case), neglected child ( 2 cases), anxiety (5 cases) and siblings' rivalry (2 cases). From all problems mentioned above, 41 cases had been categorized as psychosocial symptoms caused by multiple predisposition or precipitation factors from psychosocial problem.

Siblings' rivalry was one of psychosocial problem aspect. The definition is the feeling of jealousy, anger, competition, contrast, fight, and hate towards their siblings. The causing factors are jealous, injustice, superiority, and parent compare children to siblings. Parents idolized one child who raised their pride as parents upon another child. These reflect as bad parenting attitude and left negative impact on children who could not fulfilled their parents' pretension. This sensitive feeling of children should be treated with protective act from parents or environment to prevent the development of anxiety, depression, or low self-esteem brought to teenager or adult age [18].

Being bullied or peer victimization was one of psychosocial problems on stunted adolescent. Being bullied strongly risk factors that caused by peer pressure lead to academic failure. Bullying is an effort to force or hurt someone or some people who is psychologically or physically weaker. Bullying takes many forms; it could be physically such as hitting and asking money by force; or psychology such as mocking, spreading rumors, and cursing. It was pressuring and a traumatic experience that could be a precipitation factors to psychopathology disorder [10] [19].

Various psychosocial dysfunctions in stunted adolescent prompt to poor quality of life [20]. In this study, the psychosocial dysfunctions were not only caused by stunting, but also along with another precipitation factors such as low self esteem, family problem, childhood abused background and bullying. 
Number of family member is another risk factor that affects psychosocial problems in adolescent. Children who stay with more than 4 family members often have emotional and behavioral disorders due to lack of time and caring from parents [7]. In our study, the family number was not different between stunted and normal stature adolescent.

The predominant parenting style in both studies group was democratic parenting style whereas the smallest was permissive parenting style. No significant difference when comparing the parenting style of both groups. Democratic parenting style applied in family seems to be one of protective factors towards psychosocial dysfunction on stunted adolescents.

Nutrition became one of the factors known to affect the growth of children. Good nutrition will help to generate good growth regardless of genetic factors, which can be judged from the height that is owned by a child. But in this study, nutritional factors not become a factor for all the children who were subjected were children with good nutritional condition, not experiencing malnutrition or poor nutrition.

The limitation of the study was not conducting an evaluation using standardize instrument such as SCL-90 to examine if any parents' had mental illness that could affect the child disorder. The other limitation was only assessing the relationship of stunting towards psychosocial dysfunction in early puberty adolescent that lived in Jatinangor. Small sample size of severely stunted adolescent was related to the sample selection criteria of not having congenital disease in this group of height along with time and budget limitation.

\section{Conclusion}

There was a significant difference of psychosocial dysfunction between severely stunted and normal height adolescents, while no significant difference was found between stunted and normal height adolescents. There were some psychosocial problems and psychopatology symptoms among the adolescent groups.

\section{References}

[1] de Onis, M., Blössner, M. and Borghi, E. (2012) Prevalence and Trends of Stunting among Pre-School Children, 1990-2020. Public Health Nutrition, 15, 142-148. http://dx.doi.org/10.1017/S1368980011001315

[2] Kementerian Kesehatan Republik Indonesia (2013) Riset kesehatan dasar (RISKESDAS 2013). Kementerian Kesehatan Republik Indonesia, Jakarta, 258-259.

[3] Walker, S.P., et al. (2007) Early Childhood Stunting Is Associated with Poor Psychological Functioning in Late Adolescence and Effects Are Reduced by Psychosocial Stimulation. The Journal of Nutrition, 137, 2464-2469.

[4] Lee, J.M., et al. (2009) Short Stature in a Population-Based Cohort: Social, Emotional, and Behavioral Functioning. Pediatrics, 124, 903-910. http://dx.doi.org/10.1542/peds.2008-0085

[5] Forman, S.F. and Emans, S.J. (2000) Current Goals for Adolescent Health Care. Health Care, 36, 27-44.

[6] Sanders, R.A. (2013) Adolescent Psychosocial, Social, and Cognitive Development. Pediatrics in Review, 34, 354-359. http://dx.doi.org/10.1542/pir.34-8-354 
[7] Wille, N., Bettge, S. and Ravens-Sieberer, U. (2008) Risk and Protective Factors for Children's and Adolescents' Mental Health: Results of the BELLA Study. European Child and Adolescent Psychiatry, 17, 133-147. http://dx.doi.org/10.1007/s00787-008-1015-y

[8] Costello, E.J., Keeler, G.P. and Angold, A. (2001) Poverty, Race/Ethnicity, and Psychiatric Disorder: A Study of Rural Children. American Journal of Public Health, 91, 1494-1498. http://dx.doi.org/10.2105/AJPH.91.9.1494

[9] Voss, L.D. and Sandberg, D.E. (2004) The Psychological Burden of Short Stature: Evidence Against. European Journal of Endocrinology, 151, 29-33.

http://dx.doi.org/10.1530/eje.0.151S029

[10] Erling, A. (2004) Why Do Some Children of Short Stature Develop Psychologically Well While Others Have Problems? European Journal of Endocrinology, 151, 35-39. http://dx.doi.org/10.1530/eje.0.151S035

[11] Reijneveld, S.A., et al. (2006) Use of the Pediatric Symptom Checklist for the Detection of Psychosocial Problems in Preventive Child Healthcare. BMC Public Health, 6, 197. http://dx.doi.org/10.1186/1471-2458-6-197

[12] World Health Organization (2012) Risks to Mental Health: An Overview of Vulnerabilities and Risk Factors. WHO, Geneva, 1-14.

[13] Foy, J.M. and Perrin, J. (2010) Enhancing Pediatric Mental Health Care: Strategies for Preparing a Community. Pediatrics, 125, S75-S86. http://dx.doi.org/10.1542/peds.2010-0788D

[14] Voss, L.D. (2006) Is Short Stature a Problem? The Psychological View. European Journal of Endocrinology, 155, S39-S45. http://dx.doi.org/10.1530/eje.1.02262

[15] Sandberg, D.E. (2000) Should Short Children Who Are Not Deficient in Growth Hormone Be Treated? Western Journal of Medicine, 172, 186-189. http://dx.doi.org/10.1136/ewjm.172.3.186

[16] Xuan, X., et al. (2013) Quality of Life in Children with Short Stature: An Analysis Using PedsQL. Chinese Journal of Contemporary Pediatrics, 15, 870-874.

[17] Semba, R.D., et al. (2008) Effect of Parental Formal Education on Risk of Child Stunting in Indonesia and Bangladesh: A Cross-Sectional Study. The Lancet, 371, 322-328. http://dx.doi.org/10.1016/S0140-6736(08)60169-5

[18] Brody, L.R., et al. (1998) Mommy and Daddy Like You Best: Perceived Family Favouritism in Relation to Affect, Adjustment and Family Process. Journal of Family Therapy, 20, 269291. http://dx.doi.org/10.1111/1467-6427.00087

[19] Sandberg, D.E. (2011) Short Stature: Psychosocial Interventions. Hormone Research in Pediatrics, 76, 29-32. http://dx.doi.org/10.1159/000330151

[20] Wu, H., Li, H. and Gao, Q. (2013) Psychometric Properties of the Chinese Version of the Pediatric Quality of Life Inventory 4.0 Generic Core Scales among Children with Short Stature. Health and Quality of Life Outcomes, 11, 87. 
Submit or recommend next manuscript to SCIRP and we will provide best service for you:

Accepting pre-submission inquiries through Email, Facebook, LinkedIn, Twitter, etc. A wide selection of journals (inclusive of 9 subjects, more than 200 journals)

Providing 24-hour high-quality service

User-friendly online submission system

Fair and swift peer-review system

Efficient typesetting and proofreading procedure

Display of the result of downloads and visits, as well as the number of cited articles

Maximum dissemination of your research work

Submit your manuscript at: http://papersubmission.scirp.org/ 